ECCOMAS

Proceedia

\author{
COMPDYN 2017 \\ $6^{\text {th }}$ ECCOMAS Thematic Conference on \\ Computational Methods in Structural Dynamics and Earthquake Engineering \\ M. Papadrakakis, M. Fragiadakis (eds.) \\ Rhodes Island, Greece, 15-17 June 2017
}

\title{
UNDERSTANDING THE EFFECT OF GEOTECHNICAL PARAMETERS IN SOIL RESPONSE ANALYSIS TO EARTHQUAKE LOADING
}

\author{
Muhsin E. Rahhal ${ }^{1}$, and Mireille Antabli ${ }^{2}$ \\ ${ }^{1}$ Professor, Chair of Civil Engineering Department, Faculty of Engineering ESIB, \\ Saint Joseph University, Beirut, Lebanon \\ e-mail: $\underline{\text { muhsin.rahal@usj.edu.lb }}$ \\ ${ }^{2}$ Researcher, Civil Engineering Department, Faculty of Engineering ESIB, \\ Saint Joseph University, Beirut, Lebanon \\ e-mail: dgc.esib@usj.edu.lb
}

Keywords: Shear Wave Velocity, Shear Modulus, Plasticity Index, Ratio of Response Spectra.

\begin{abstract}
Seismic ground motions observed on soft soil sites can be considerably larger than would be expected for rock sites located at similar epicenter distances. Lebanon is situated in the eastern Mediterranean, an area that is seismically active. In order to understand the effect of geotechnical parameters on the seismic soil response, the paper presents the results of the analysis of five deposits both clayey and sandy with different depths. A detailed study is carried out in order to understand the effect of phreatic level, plasticity index, and input earthquake acceleration on soil response. The amplification is studied both in terms of soil surface acceleration change as well as the ratio of response spectra (RRS). Accelerations measured at the soil surface were as much as five times higher than those measured on the neighboring rock, when rock accelerations were less than $10 \% \mathrm{~g}$, the amplification factor being less in the presence of sandy soils. Less amplification was observed in the unsaturated deposits, and the ratio of response spectra increased with the plasticity index.
\end{abstract}

(C) 2017 The Authors. Published by Eccomas Proceedia.

Peer-review under responsibility of the organizing committee of COMPDYN 2017.

doi: $10.7712 / 120117.5477 .18166$ 


\section{INTRODUCTION}

It is known that each soil type responds in a different way when it is subjected to earthquake ground motion. The study of local site effects on seismic ground motions is an important feature of geotechnical earthquake engineering. Seismic waves reflection in the loose surface soil layer may yield resonance or amplification at certain frequencies depending on layer thickness. Each and every site at the same distance from the earthquake source may have a special soil response during the earthquake. Site effects were particularly put in evidence during the 1985 Mexico Earthquake. Nowadays, the method with which site amplification is estimated is still a major concern and under investigation among seismologists and earthquake engineers. Developing methods for assessing the nature and potential of soil amplification is important, especially when choosing the location and design of critical and essential facilities [1], [2], [3]. Studying soil response means understanding earthquake source, source nature and distance, wave path, geologic context, upper soil properties, topography and primarily site effects [4], [5]. The worldwide problem of site effects may be illustrated by local ground motion amplification, resonance or strong liquefaction potential [6], [7]. Waves generated during an earthquake are characterized by their spreading velocity. If the latter is relatively stable deep in the earth's crust, it becomes highly variable in the immediate vicinity of the surface, because both compression and shear waves are directly linked to soil or rock compactness. For example, shear wave velocity can be as high as $3000 \mathrm{~m} / \mathrm{s}$ in strong granite and as low as $500 \mathrm{~m} / \mathrm{s}$ in the same granite if it is weak or altered. Also, shear wave velocities may be as high as $1000 \mathrm{~m} / \mathrm{s}$ in consolidated dense sediments, and less than $100 \mathrm{~m} / \mathrm{s}$ in loose soils. Site effects are frequently linked to loose ground conditions such as recent sedimentary fill.

The goal of the present research is to highlight the importance of the geotechnical parameters which are sometimes neglected by practicing civil engineers when applying codes and not taking into consideration special site conditions existing in the proposed project location. All the analyses underline the interest that should be given to the geotechnical parameters and their effect. This paper will give a wrap up of research results obtained by the author in the last years [8], [9], [10], [11], and covering different aspects of soil acceleration amplification and liquefaction problems in Canada. Liquefaction potential analysis has been realized earlier for different soil deposits in Lebanon [12]. In this paper, typical soil deposits will be analyzed and the significance of the effect of geotechnical parameters (plasticity index, water table, soil acceleration) on soil response will be addressed through an exhaustive parametric study.

\section{LEBANON SEISMICITY}

Earthquake geotechnical engineering problems are of major concern to Lebanon since the country lies over an estimated $1000 \mathrm{~km}$ long fracture system which extends from the seafloor spreading in the Red Sea to the Taurus Mountains in southern Turkey. This fracture system is a main tectonic feature in the Eastern Mediterranean and is known as the Levantine or the Dead Sea fault system. The Levant fracture is similar to the fault system in California, since it has given rise, at different parts along its length and in different time intervals, to major destructive earthquakes of varying magnitudes. Lebanon is zoned today as $0.25 \mathrm{~g}$ earthquake design acceleration. In the present parametric study, the El Centro signal having $\mathrm{a}_{\max }$ equal to $0.348 \mathrm{~g}$ will be used and then scaled to represent many loading scenarios that might occur in Lebanon in the event of an earthquake induced by the many faults affecting the country. 


\section{METHODOLOGY OF ANALYSES}

Sources of information and the database that was used in the present study included topographic and geologic maps, as well as engineering geology, geotechnical and deep boring data. The covered studies may provide a reasonably well first approximation of the characterization of soil (rock) layers and geotechnical properties. The analysis comprised five Lebanese soil deposits with different thicknesses, a varying water table level, and the presence of both clay and sand layers. As far thicknesses are concerned, soil deposits (types 1 and 3) are the deepest (around 30m) while soil deposits (types 2, 4 and 5) are shallower (around 15m). Types 1 and 2 alternate granular and clayey layers, type 3 is essentially made of clay layers while types 4 and 5 are purely sand layers. The type 1 soil deposit $(31.5 \mathrm{~m}$ thickness, alternating loose gravelly, sandy, and silty clay layers) is near the Litani river in southern Lebanon; the type 2 soil deposit (13m thickness, mainly sandy and silty clay layers) is in Beirut downtown; the type 3 soil deposit (29.5m thickness, sandy clay layers) is in Beirut near Beirut river; the type 4 soil deposit (15m thickness, silty and clayey sand layers) is in Beirut Suburb Chiyah; and the type 5 soil deposit (16m thickness, sandy layers) is in Beirut Suburb airport area. The geotechnical field and laboratory investigations of the involved soils, allowed the determination of the soil properties required for soil acceleration amplification calculations. Main properties in the analysis are the small strain shear modulus $G_{\max }$ or the shear wave velocity $V_{s}$, and the small strain damping ratio $\mathrm{D}$. The studied fundamental periods ranging from $0.2 \mathrm{~s}$ to $0.7 \mathrm{~s}$ are representative of soil deposits found in the greater Beirut area as well as in many other places all over Lebanon. Also, these fundamental periods appeared to be variable for soil deposits. The possible reasons behind this variability were attributed particularly to the variability of material properties including thickness of sediments and density that led to the variability of shear wave velocity of soils. Although the soil deposits included different layers, an average representative value of some parameters is given in Table 1; the fundamental period (very small strain) for each deposit is also shown in Table 1 . The shear wave velocity of the underlying rock was taken as $2500 \mathrm{~m} / \mathrm{s}$. The information on rock is quite essential as one should know if the rock behaves as a rigid layer. In reality, however, all rocks are to some extent deformable and thus it is desirable to determine how stiff the rock must be before it can reasonably satisfy this requirement. The influence of the rigidity of rock and the effect of the rigidity contrast between soils and underlying rock are currently being analyzed by the authors.

\begin{tabular}{cccccc}
\hline SOIL DEPOSIT & Type 1 & Type 2 & Type 3 & Type 4 & Type 5 \\
\hline $\mathrm{V}_{\mathrm{s}}(\mathrm{m} / \mathrm{s})$ & 209 & 226 & 188 & 273 & 277 \\
$\mathrm{~T}(\mathrm{~s})$ & 0.603 & 0.230 & 0.638 & 0.220 & 0.231 \\
$\mathrm{G}_{\max }(\mathrm{MPa})$ & 74 & 87 & 64 & 141 & 145 \\
$\mathrm{D}(\%)$ & 2 & 3 & 2 & 2 & 2 \\
\hline
\end{tabular}

Table 1. Representative average soil deposits properties.

Many analyses were carried out on these soil deposits in order to cover a wider range of eventual soil acceleration amplification, with a special attention given to the following three aspects: The plasticity index of clays, the role of water table level, and the initial rock peak horizontal acceleration. Adapted computer programs with equivalent linear soil response 
analysis in time and frequency domains were used. The necessary input data are the time history of an earthquake, the soil profile, and the dynamic soil properties. The earthquake time history can be a corrected and scaled recorded accelerogram. The selected earthquake input signal was the El-Centro earthquake, with scaled peak horizontal acceleration. The soil profile consists of the layers and their corresponding thicknesses, initial damping ratio, unit weights and small strain shear modulus. The dynamic soil properties are defined by damping ratio and shear modulus degradation curves found in literature and that give the equivalent damping and the secant shear modulus as a function of strain [8].

\section{RESULTS AND DISCUSSION}

The factor of amplification was estimated in two methods: first as the ratio of the peak horizontal surface soil acceleration $\mathrm{a}_{\text {surf }}$ to the input peak earthquake rock horizontal acceleration $a_{\max }\left(a_{\text {surf }} / a_{\max }\right)$; and secondly as the maximum (FA) of the ratio of response spectra RRS ( $F A=$ maximum of ratio of surface soil to input rock acceleration response spectra). In fact, a useful tool to study the amplification phenomenon is the curve of Ratio of Response Spectra (termed RRS) versus period T. Figure 1 shows the modification in the factor of amplification $\left(a_{\text {surf }} / a_{\max }\right)$ as a function of the plasticity index of the clays. Figure 2 shows the modification of the factor of amplification of the RRS method as a function of the varying plasticity index. The effect of varying the water table level on the Factor of amplification is given in Figure 3 $\left(F A=a_{\text {surf }} / a_{\max }\right)$ and Figure $4(F A=$ maximum of $R R S)$. The outcome of selecting initial rock input peak horizontal acceleration $a_{\max }$ after scaling the initial earthquake acceleration $a_{\max }$ initial is given in Figure $5\left(\mathrm{FA}=\mathrm{a}_{\mathrm{surf}} / \mathrm{a}_{\max }\right)$ and Figure 6 (FA= maximum of $\left.\mathrm{RRS}\right)$.

Both Figures 1 and 2 highlighting the role of the plasticity index show that a higher plasticity index increases the factor of amplification whatever its mode of evaluation $\left(a_{\text {surf }} / a_{\max }\right.$ or FA). Analysis was done by changing the plasticity index of the clayey layers in deposits of types 1 to 3 containing such layers. The three soil deposits give the same tendency with higher amplification factors for type 2 soil deposit due to resonance effects between the soil fundamental period and the earthquake signal. It was noticed that the peak RRS values for soil deposit type 2 were measured at a period of $0.25 \mathrm{~s}$ near the corresponding fundamental period of the soil deposit type 2. The factor of amplification measured in the time domain is lower than the one measured in the frequency domain. In the time domain, the factor of amplification is lower than 1 in the case of very low plasticity indices yielding a sand-like behavior.

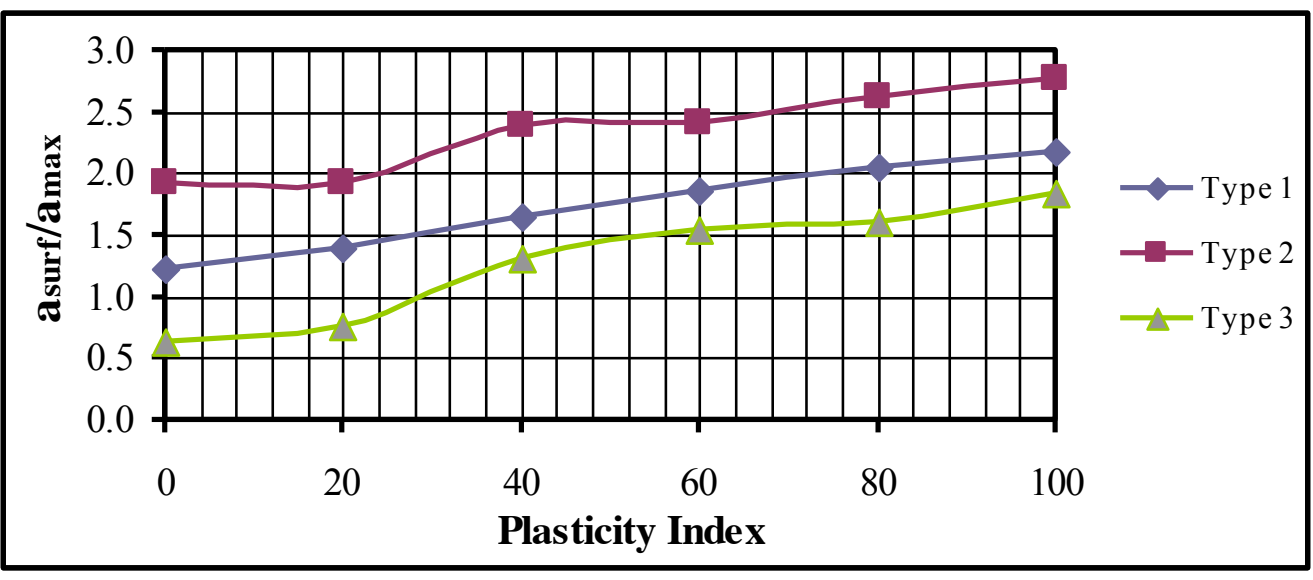

Figure 1. Time domain acceleration amplification as a function of plasticity index 


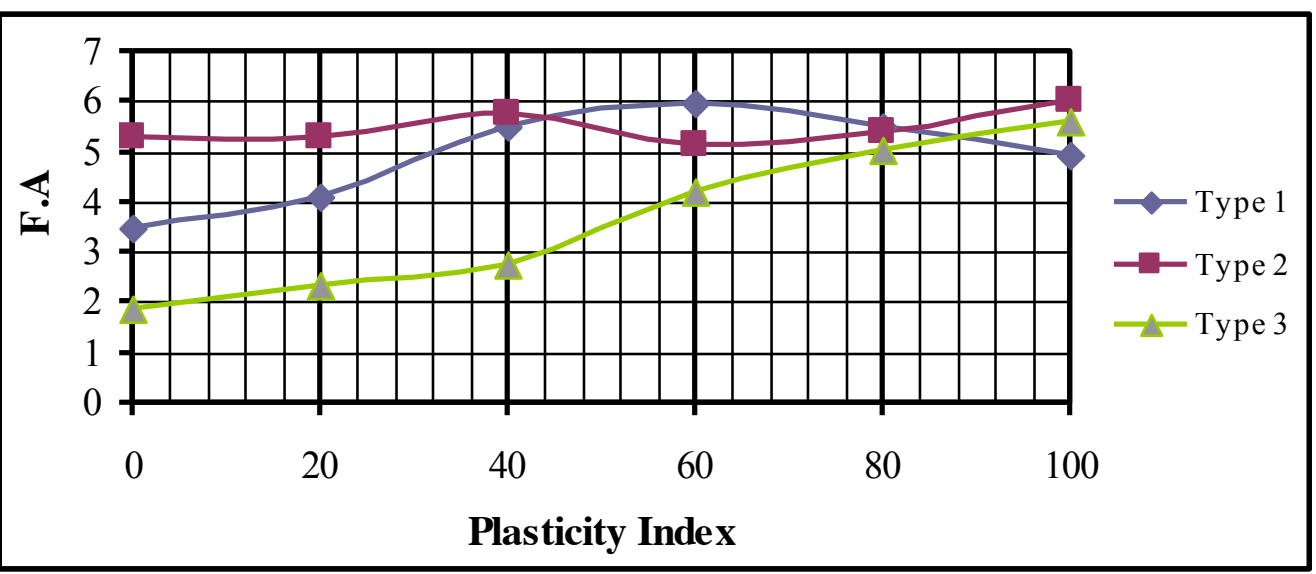

Figure 2. Frequency domain acceleration amplification as a function of plasticity index

As far as the role of the presence of water table is concerned, both Figures 3 and 4 show that the water table does not influence the seismic response of sandy soil deposits of types 4 and 5. For the soil deposit type 3, the factor of amplification decreases with a lower water table. Soil deposit type 2, which has half the thickness of type 3, does not give a clear trend except for the fact that both clayey soil deposits of types 2 and 3 are affected by water table level. The effect of input peak horizontal acceleration is analyzed in Figures 5 and 6.

The input peak horizontal acceleration of the earthquake $(0.35 \mathrm{~g})$ has been scaled between $0.2 \mathrm{a}_{\max }(0.07 \mathrm{~g})$ and $1.4 \mathrm{a}_{\max }(0.49 \mathrm{~g})$ in order to put emphasis on the effect of the input acceleration on seismic soil response. While a very slight trend of decreasing factor of amplification for sandy soil types 4 and 5 is observed (Figures 5 and 6) with an increasing input earthquake acceleration, clayey-like soils deposits (types 1 and 3) denote a much higher decrease in amplification. As far as soil deposit type 2 is concerned, a higher factor of amplification is measured (Figures 5 and $6, \mathrm{a}_{\text {surf }} / \mathrm{a}_{\max }$ and FA respectively). Again, it is useful to mention that this is due to resonance effects between the soil deposit type 2 fundamental period and the earthquake signal fundamental period.

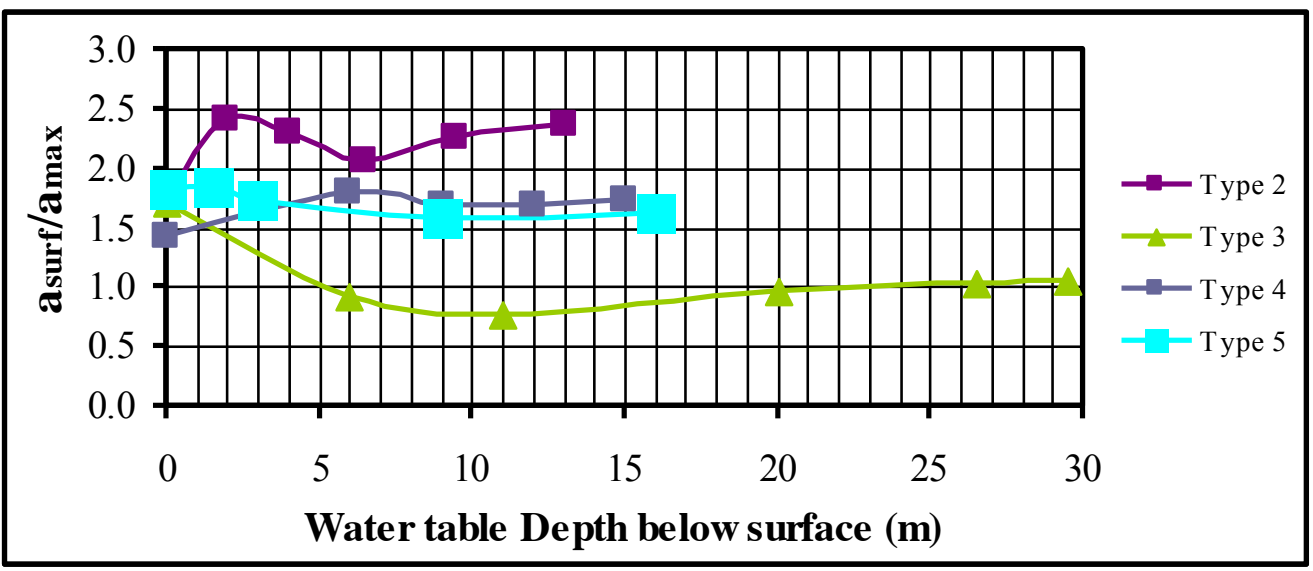

Figure 3. Time domain acceleration amplification as a function of water table level 


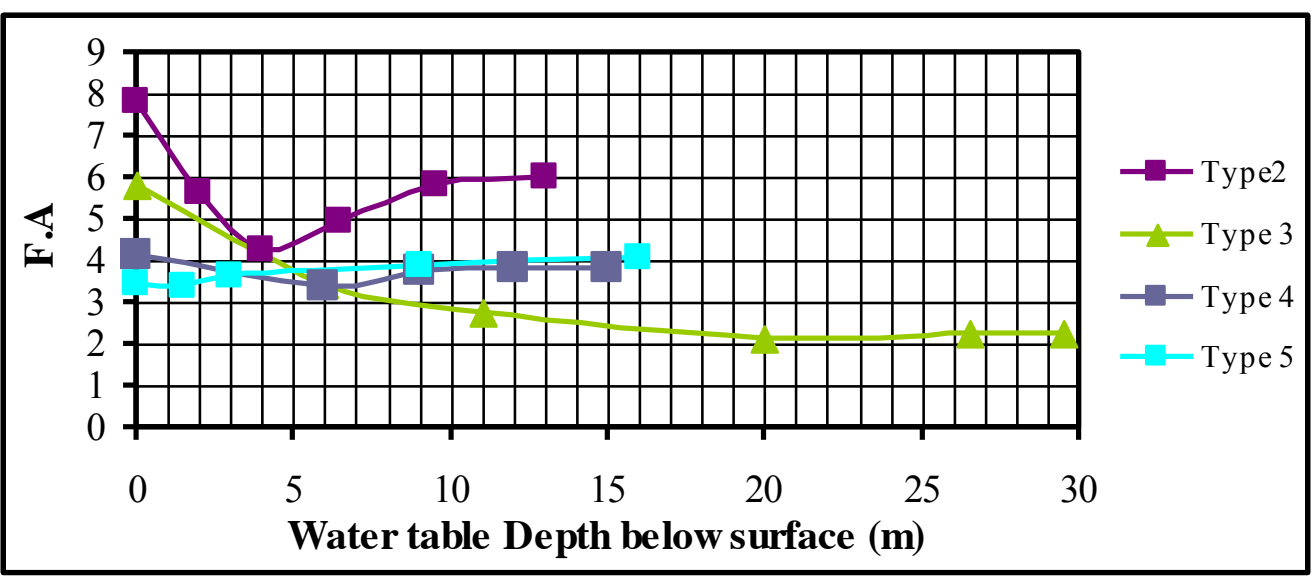

Figure 4. Frequency domain acceleration amplification as a function of water table level

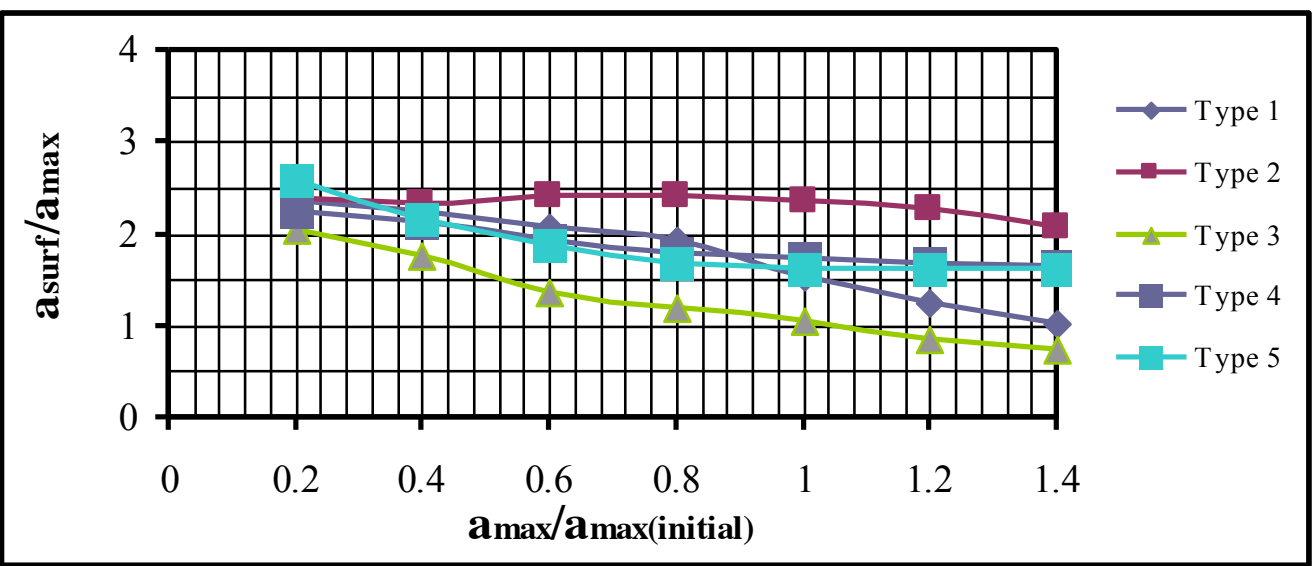

Figure 5. Time domain acceleration amplification as a function of input $\mathrm{a}_{\max }$

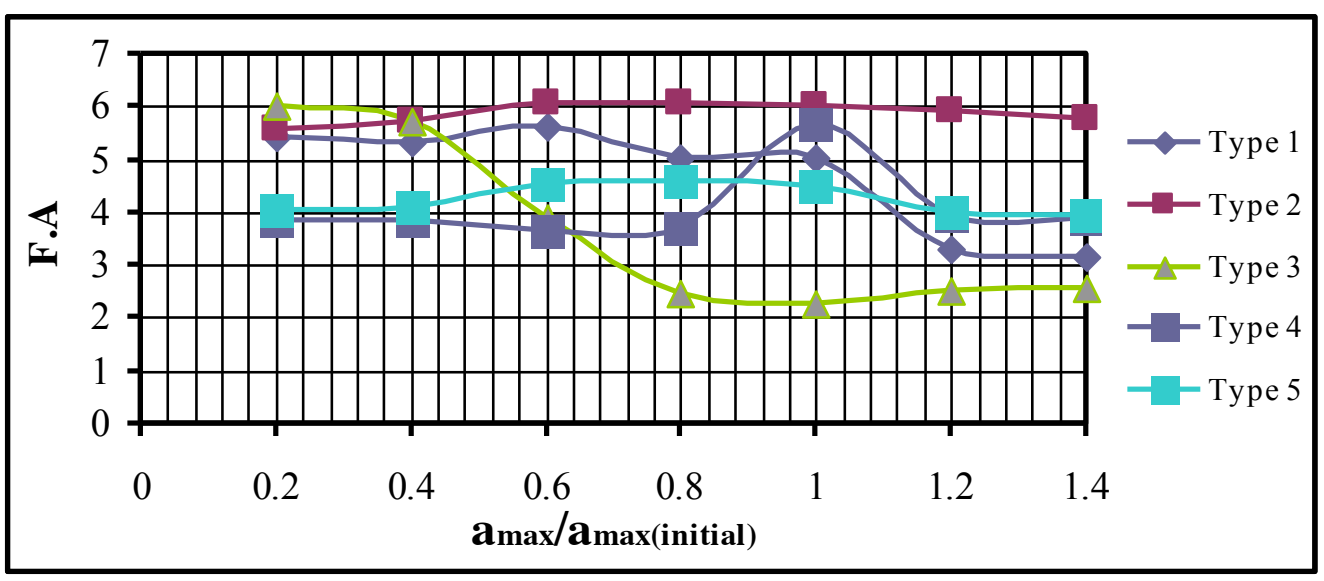

Figure 6. Frequency domain acceleration amplification as a function of input $\mathrm{a}_{\max }$

On the other hand, in order to more understand the role of the different parameters and their influence on the final results, a detailed analysis has been carried out in the frequency domain mainly by observing the change in RRS as a function of the spectral periods. Emphasis is put on soil types 1 and 3 because they are the deepest deposits with a thickness of 
around 30m. Figures 7 and 8 show respectively RRS values obtained for different plasticity indices in the case of soil types 1 and 3 respectively. Figures 9 and 10 show the change in RRS values for different input acceleration on the rock in the case of soil types 1 and 3 respectively. Figure 11 shows the effect of varying water level on RRS in the case of soil type 3. At this point, it is important to underline that soil type 1 is made of alternating sandy gravel and clay layers, while soil type 3 is constituted of clay layers only.

As for the results of the analysis it is obvious that higher peaks are obtained with intermediate to high plasticity indices (Figure 7 and 8). In Figure 7 higher peaks are measured for plasticity indices greater than $40 \%$ with the highest $\mathrm{RRS}(\mathrm{RRS}=5.95$ at $\mathrm{T}=0.84 \mathrm{~s}$ ) obtained for IP $=60 \%$. In Figure 8 , a clearer trend is observed in the case of soil type 3 made only of clay layers; the peaks become higher with the increase of plasticity index in the form of a linear relation. The highest peak ( $R R S=5.59$ at $\mathrm{T}=1.14 \mathrm{~s}$ ) is obtained for the high plasticity index IP $=100 \%$. For clayey soils of type 3 (Figure 8), it is important also to mention the presence of smaller peaks at lower periods ( $R R S=2.33$ at $\mathrm{T}=0.44 \mathrm{~s}$ for $\mathrm{IP}=100 \%)$. This is attributed to another mode of resonance. Finally, in the case of lower plasticity indices (less than 20\%) RRS values diminish drastically in the presence of clay layers only (Figure 8) while this trend is less obvious in soil deposits containing sandy and clayey layers (Figure 7).

The input rock acceleration initially used as reference is $a_{i n i t}=0.348 \mathrm{~g}$. As for the effect of the value of initial input rock acceleration on the response, Figures 9 and 10 show that for both soil types 1 and 3 , the high RRS peaks correspond to smaller accelerations $\left(a_{\max } / a_{\text {init }}\right.$ less than 0.6 yielding maximum input rock accelerations less than $0.21 \mathrm{~g}$; in Figure 9, higher peaks are measured for $\mathrm{a}_{\max } / \mathrm{a}_{\text {init }}$ less than 1 with the highest $\mathrm{RRS}(\mathrm{RRS}=5.61$ at $\mathrm{T}=0.80 \mathrm{~s})$ obtained for $\mathrm{a}_{\max } / \mathrm{a}_{\text {init }}=0.6$. In Figure 10, a net trend is observed in the case of soil type 3 made only of clay layers; the peaks becoming obviously higher when a smaller input acceleration is used, with the RRS getting higher with the decrease of input acceleration in the form of a linear relation. The highest peak (RRS $=6.00$ at $\mathrm{T}=1.12 \mathrm{~s}$ ) is for $\mathrm{a}_{\max } / \mathrm{a}_{\text {init }}$ equal to 0.2 yielding a maximum input rock acceleration of $0.07 \mathrm{~g}$. In both Figures 9 and 10 , it is worth to note the presence of smaller peaks at lower periods, with the peaks being more detected in the case of soil type 3 as in the case of the effect of plasticity index. This is again attributed to another mode of resonance that becomes much more evident in the presence of clayey layers only (soil type3). For high input acceleration, peaks are less marked and shift to higher periods. In the case of soil type 1 (Figure 9), smaller peaks are measured in the case of higher input accelerations at periods of around 1s. One may emphasize the following observation: The higher the input acceleration, the lower the RRS peak and the higher the period. This is logic because the higher the acceleration, the lower the dynamic properties, hence the higher the period. As a final point, Figure 11 proves that for soil type 3; the closer the water table to the surface, the weaker the soil and the higher the RRS peak. When the water table is at surface (WT=0 m), $\mathrm{RRS}=5.84$ at $\mathrm{T}=0.84 \mathrm{~s}$, a lower water table indicates a shift of RRS peak towards high periods.

Finally, with the purpose of showing the results of the analyses in a larger frame, Figure 12 puts together previously obtained results on soft North American soils as well as the results of the present research [13], [9], [11]. It is interesting to note that analyzed seismic Lebanese soils response yield a general trend similar to the one obtained in the case of soft Canadian soils [9]. The higher soil acceleration in the case of Canadian soils may be explained by their soft consistency. In all cases the curve presented by [13] underestimates the soil acceleration. This underestimation of soil acceleration has been observed before, with both the results of Mexico 1985 and the Loma Prieta 1989 earthquakes. Further analysis is to be carried out in 
the case of Lebanese soils to better validate the proposed curve in Figure 12, although the obtained trend (decreasing soil acceleration in the case of higher rock acceleration) is conform to other literature findings putting in evidence nonlinear behavior.

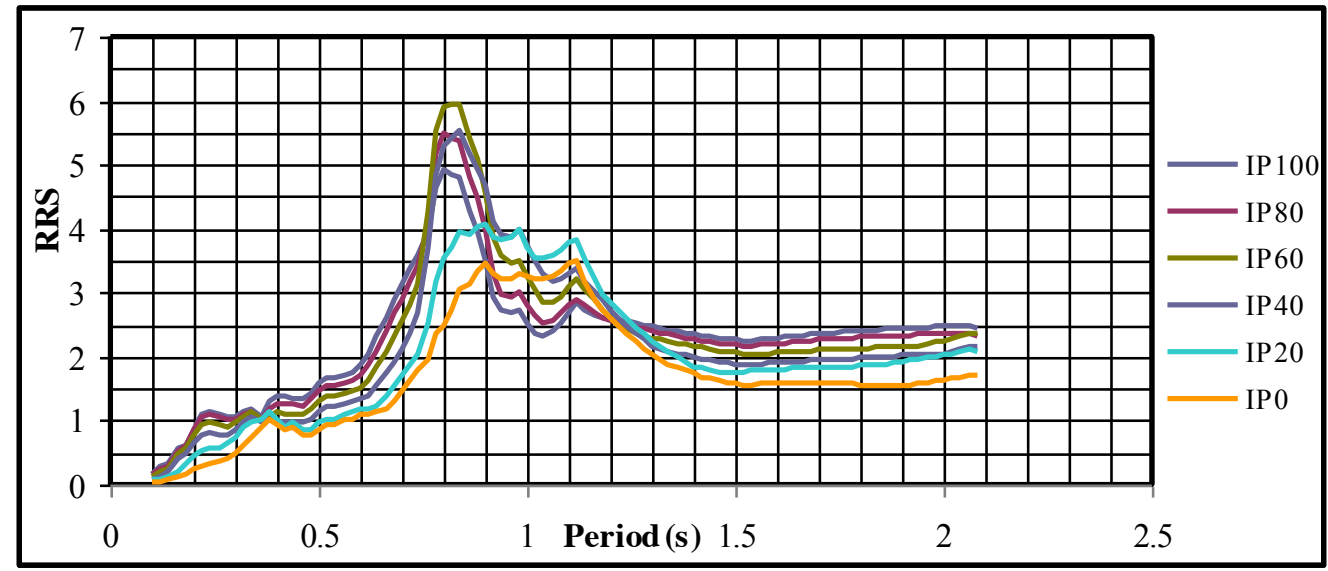

Figure 7. RRS for soil type 1 as a function of different plasticity indices

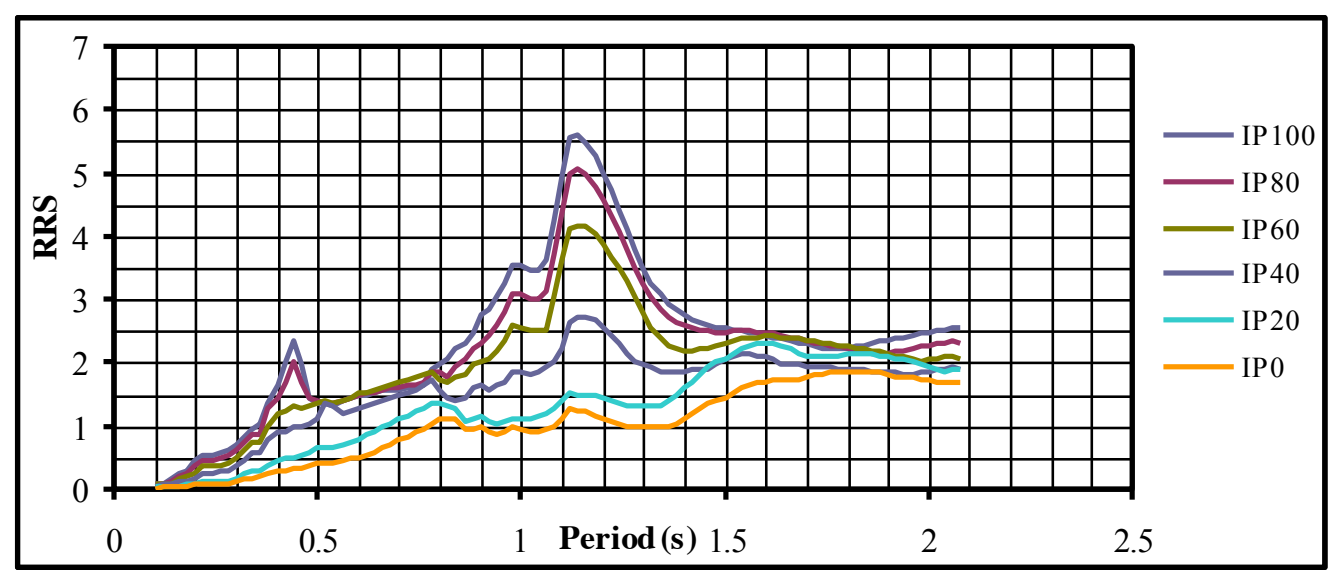

Figure 8 . RRS for soil type 3 as a function of different plasticity indices

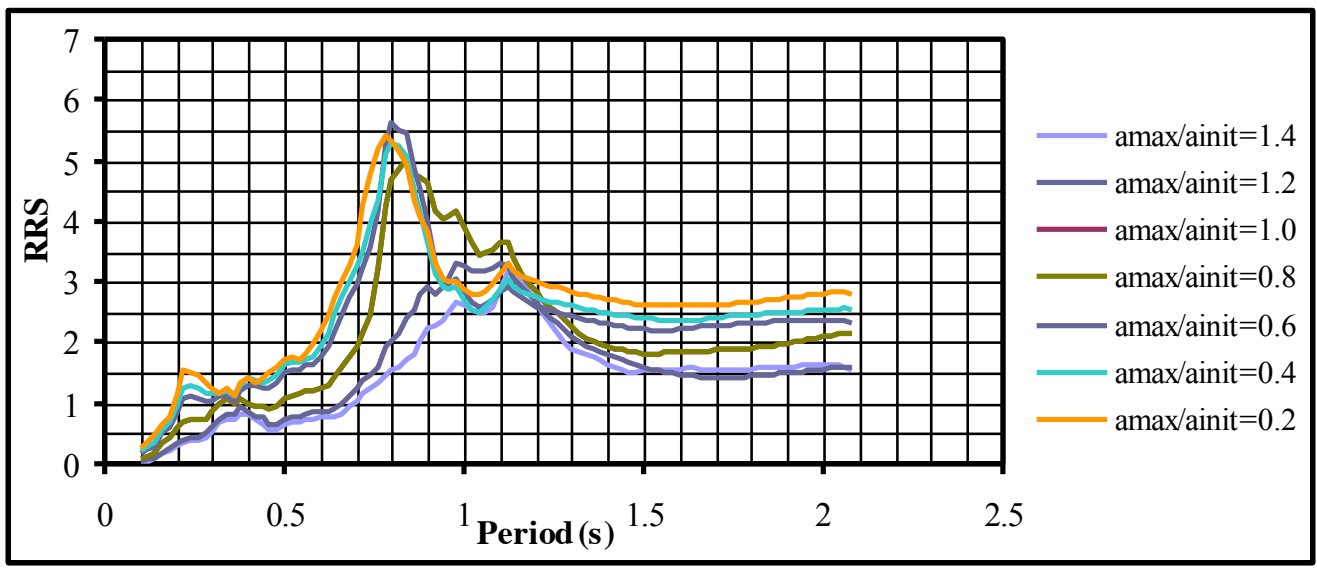

Figure 9. RRS for soil type 1 as a function of input acceleration 


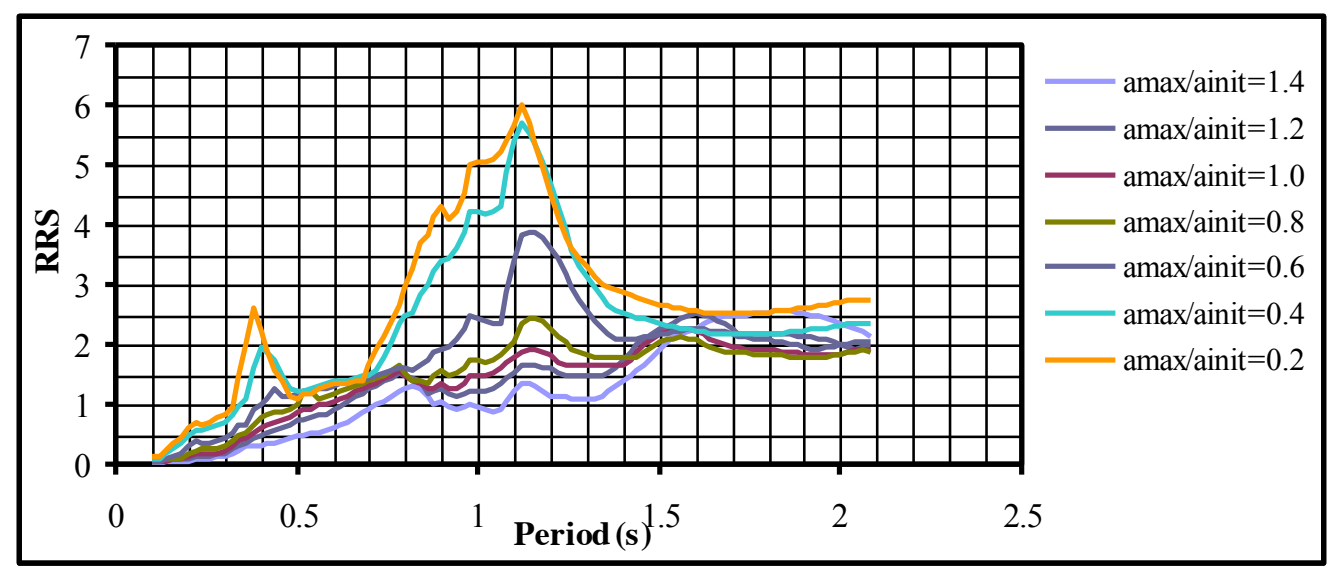

Figure 10. RRS for soil type 3 as a function of input acceleration

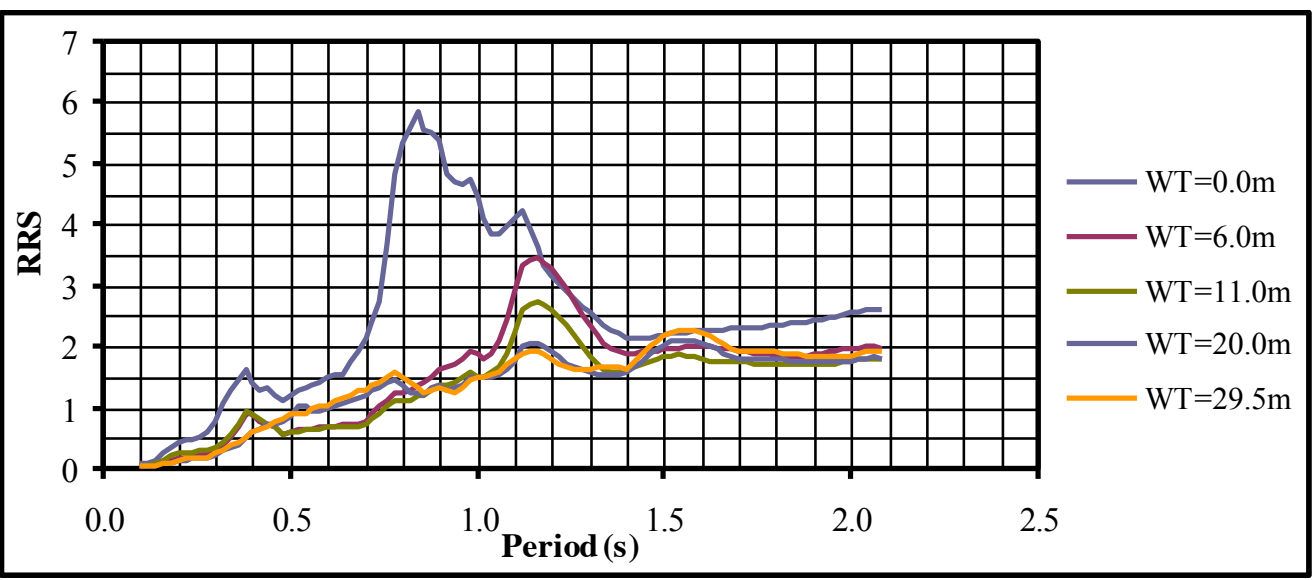

Figure 11. RRS for soil type 3 as function of water table (WT) depth in the profile

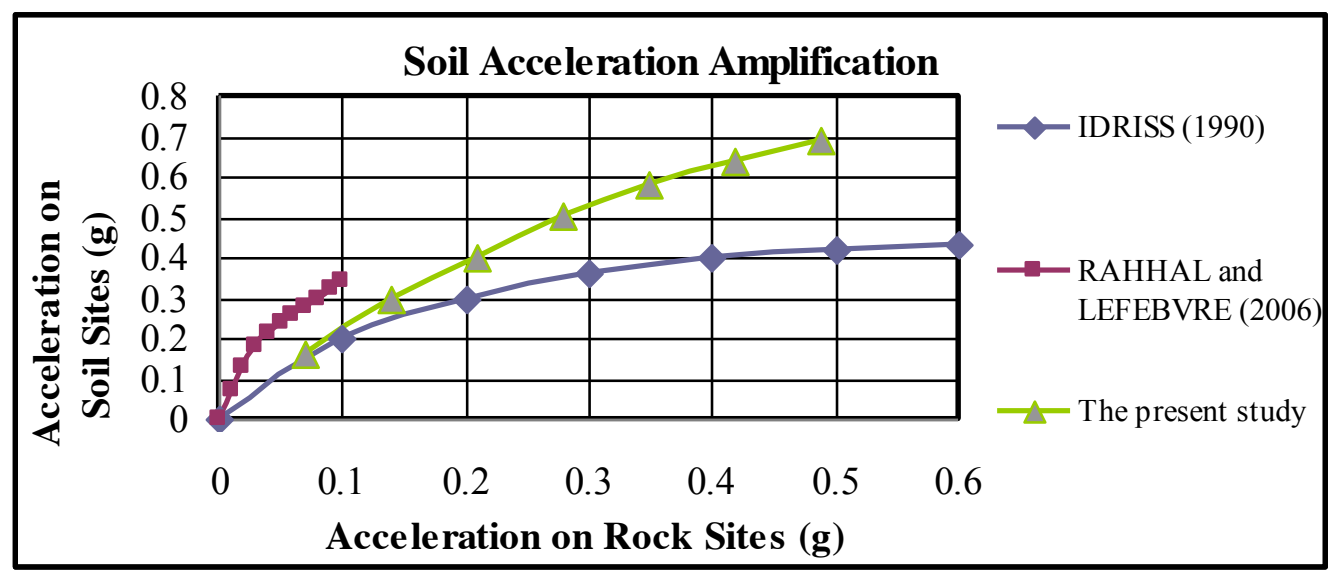

Figure 12. Proposed relation between soil and rock accelerations

\section{CONCLUSIONS}

A significant difference in seismic soil response, as far as surface acceleration is concerned, was observed when comparing clayey and sandy deposits: higher amplifications were measured in the presence of clay confirming previous observations in Mexico (1985), Saguenay 
(1988) and Loma Prieta (1989). The analysis was carried out in terms of ratio of response spectra to underline the significance of frequency content in seismic soil response. The effects of soil shear modulus degradation on soil surface acceleration are taken into account. The importance of shear modulus degradation due to seismic loading is linked to the threshold shear strain that separates elastic deformations from larger deformations. Further analysis is to be carried out in the case of Lebanese soils. An important work is currently underway to understand the behavior of Lebanese soils under earthquake loading. Case studies and analyses presented in this research will bring about a better understanding of the earthquake geotechnical context of Lebanese soils that can be extrapolated to neighboring countries soils. The obtained results should form a basis for any subsequent analysis of site effect problems during major earthquake events that might hit the area. Finally, the emphasis was on the importance of the geotechnical chapter in earthquake engineering.

\section{REFERENCES}

[1] Dobry, R., Ramos, R., Power, M.S., "Site Factors and Site Categories in Seismic Codes," Technical Report MCEER-99-0010, Buffalo, State University of New York, USA, July 1999.

[2] Finn, W.D.L., State of the Art of Geotechnical Earthquake Engineering Practice, Soil Dynamics and Earthquake Engineering Journal, 20, 1-15, 2000.

[3] Finn, W.D.L., and Wightman, A., Ground Motion Amplification Factors for the Proposed 2005 Edition of the National Building Code of Canada, Canadian Journal of Civil Engineering, 30, 272-278, 2003.

[4] Adams, J., Soil Amplification in Ottawa from Urban Strong Ground Motion Records, Proceedings of the Ninth Canadian Conference on Earthquake Engineering, Ottawa, Canada, Paper No. 1162, June 2007.

[5] Crow, H., Hunter, J.A., Pugin, A., Gooks, G., Motasedian, D., and Khasheshi-Banab, K., Shear Wave Measurements for Earthquake Response Evaluation in Orleans, Ontario, Proceedings of the 60th Canadian Geotechnical Conference, Ottawa, Canada, 2, 871879, 2007.

[6] Kockar, M.K., and Akgun, H., Evaluation of Site Characterizations and Site Effects of the Ankara Basin, Turkey, Proceedings of the 4th International Conference on Earthquake Geotechnical Engineering, Thessalonica, Greece, Paper No. 1241, June 2007.

[7] Komak Panah, A., Hafezi Moghaddas, N., Ghayamghamian, M.R., Motosaka, M., Jafari, M.K. and Uromieh, A., Site Effect Classification in East-Central Iran, Journal of Seismology and Earthquake Engineering, 4, No 1, 37-46, 2002.

[8] Rahhal, M.E., Lefebvre, G., Characterizing Shear Moduli Reduction in Soils Cyclic Behavior, Proceedings ASCE Geo Congress, Atlanta, USA, CD, February 2006.

[9] Rahhal, M.E. and Lefebvre, G., Analysis of a Clay Deposit Seismic Response in Eastern Canada, Proceedings of the First European Conference on Earthquake Engineering and Seismology, Geneva, Switzerland, CD, September 2006.

[10] Rahhal, M.E., A Geotechnical Characterization of Site Effects during Earthquakes, Proceedings of the International Symposium in Earthquake Engineering, commemorating 30 years from the 1977 Vrancea Earthquake, Bucharest, Romania, CD, March 2007. 
[11] Rahhal, M.E., Understanding Site Effect during the 1988 Saguenay Earthquake in Canada, Proceedings of Earthquake and Tsunami WCCE-ECCE-TCCE joint Conference, Istanbul, Turkey, 122-124, June 2009.

[12] Rahhal, M.E., Comprendre les Méthodes d'Évaluation du Potentiel de Liquéfaction des Sols, Proceedings of the 4th Canadian Conference on Geohazards, Québec, Canada, Presse de l'Université Laval, 117-124, May 2008.

[13] Idriss, I.M., Response of Soft Soil Sites during Earthquakes, Proceedings of H. Bolton Seed Memorial Symposium, 273-289, 2006. 